\title{
Underwater shock response of circular HSLA steel plates
}

\author{
R. Rajendran ${ }^{\mathrm{a}}$ and K. Narasimhan ${ }^{\mathrm{b}, *}$ \\ ${ }^{\mathrm{a}}$ Naval Science \& Technological Laboratory, \\ Visakhapatnam 530 027, India \\ ${ }^{\mathrm{b}}$ Department of Metallurgical Engineering \& \\ Materials Science, Indian Institute of Technology, \\ Bombay 400 076, India
}

Received 17 August 1999

Revised 13 May 2000

Studies on shock response of circular plates subjected to underwater explosion is of interest to ship designers. Noncontact underwater explosion experiments were carried out on air backed circular High Strength Low Alloy (HSLA) steel plates of $4 \mathrm{~mm}$ thickness and $290 \mathrm{~mm}$ diameter. The experiments were carried out in two phases. In the first phase, strain gauges were fixed at intervals of $30 \mathrm{~mm}$ from the centre of the plate and strains were recorded for the shock intensity gradually increasing to yielding. Semi-analytical models were derived for the elastic strain prediction which showed good agreement with the experiments. Dynamic yield stress and the shock factor for yielding were established. In the second phase, individual plates were subjected to increasing shock severity until fracture and the apex bulge depth and the thickness strains were measured. Empirical models were derived to predict the plastic deformation which were validated through a fresh set of experiments. Analysis of the fractured surface by visual examination showed that there was slant fracture indicating ductile mode of failure and the same was corroborated by Scanning Electron Microscopic (SEM) examination.

\section{Introduction}

Air backed circular plates are extensively investigated for underwater shock response because they represent panels of ships plating [6,12]. During noncontact underwater explosion, if the explosive power is small enough or the stand off is large, stresses built up

\footnotetext{
*Corresponding author. E-mail: nara@met.iitb.ernet.in.
}

in the circular plate are within its elastic range. As the explosive power is increased, there is yielding of plates preceding plastic deformation and fracture. Cole [1], in his analysis of an infinite free plate, derived the kickoff velocity attained by a plate when subjected to underwater explosion. Ezra [4] showed that the velocity distribution on a clamped circular plate due to an underwater shock wave compared well with the analytical prediction except at the clamping edges. Kennard [14] presented the interaction between the target plate and the shock wave. Jones [11] performed underwater explosion on air and water backed circular aluminium and composite plates to measure radial and tangential strains.

Explosive plastic deformation of circular plates was carried out by Travis et al. [23] and Johnson et al. [9,10] to investigate the effects of underwater explosion on various thicknesses and different materials. Finnie [5] showed that the impulse per unit deformation was proportional to the thickness of the plate. Remmerswaal [20] showed that there were structural changes in the metal causing twinning and phase transformation when an underwater shock wave passed through. Smith et al. [21] examined the failure of circular plates by subjecting them to uniformly distributed impulse by sheet explosive. Nurick $[17,18]$ derived an empirical solution for predicting the deflection of circular plates subjected to impulse by sheet explosive.

In this investigation, underwater explosion experiments were carried out on a circular High Strength Low Alloy (HSLA) steel plate in the elastic range and the dynamic strains were recorded at close intervals. Semianalytical models were derived to predict the elastic strains and compared with the experimental data. The shock intensity was gradually increased to the point of yielding to estimate the dynamic yield stress and shock factor required for the yield onset. Experiments were also carried out in the plastic range on plates upto the point of fracture. An empirical model was developed to predict the plastic deformation. This model was validated through a fresh set of experiments. Fracture analysis was carried out on the failed circular plate both by 
Table 1

Chemical composition of the High Strength Low Alloy (HSLA) Steel in weight (\%)

\begin{tabular}{ccccccccc}
\hline Element & $\mathrm{C}$ & $\mathrm{Mn}$ & $\mathrm{Ni}$ & $\mathrm{Cr}$ & $\mathrm{S}$ & $\mathrm{Si}$ & $\mathrm{Cu}$ & $\mathrm{P}$ \\
\hline $\begin{array}{c}\text { Content } \\
(\%)\end{array}$ & 0.12 & $0.6-0.8$ & $0.8-1.1$ & $0.6-0.9$ & 0.035 & $0.5-0.8$ & $0.4-0.6$ & 0.035 \\
$\max$ & & & & & & & $\max$ \\
\hline
\end{tabular}

Table 2

Mechanical properties of the High Strength Low Alloy (HSLA) Steel

\begin{tabular}{ccc}
\hline Yield stress $(\mathrm{MPa})$ & Ultimate tensile stress $(\mathrm{MPa})$ & Elongation $(\%)$ \\
\hline 400 & 560 & 28 \\
\hline
\end{tabular}
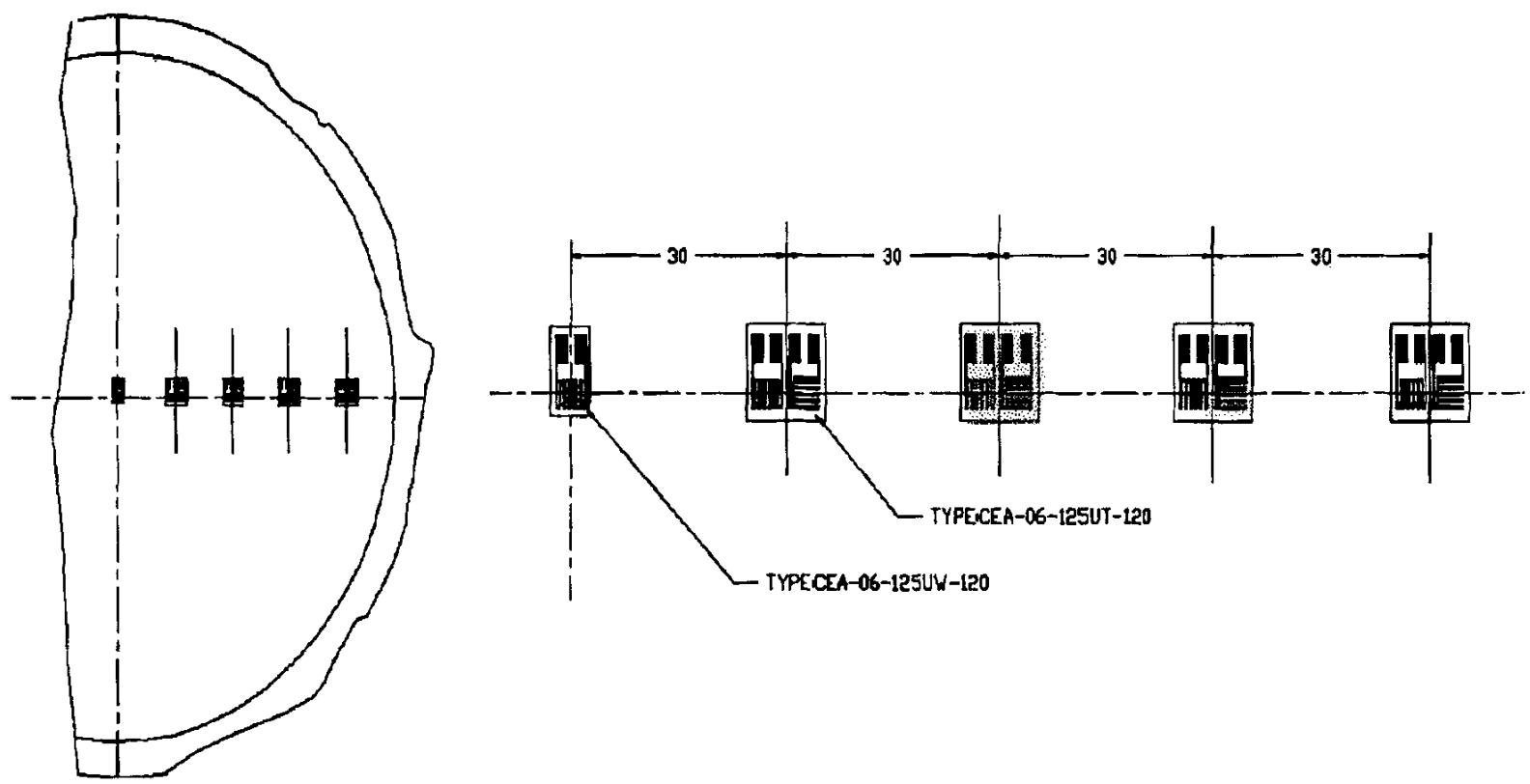

Fig. 1. Schematic of the location of strain gauges on the HSLA steel circular plate.

visual examination and Scanning Electron Microscopic (SEM) examination.

\section{Experimental}

The High Strength Low Alloy (HSLA) steel plates used for this investigation were $4 \mathrm{~mm}$ in thickness having an Young's modulus of $211 \mathrm{GPa}$ and Poisson's ratio of 0.29 . The chemical composition and mechanical properties of these hot rolled and not heat treated plates are given in Tables 1 and 2 respectively.

The circular plate chosen for investigation was $550 \mathrm{~mm}$ in diameter with an exposed area of $290 \mathrm{~mm}$ diameter. These dimensions meet the condition of an infinite plane plate since the shock pulse generated during the experiments had a maximum length of $35 \mu \mathrm{s}$ which is much less when compared to the diffraction time of the plate $(96.6 \mu \mathrm{s})$ [1]. Also, the plastic deflection undergone by the plate is proportional to the impulse imparted on it since the natural period of oscillation of the plate $(4080 \mu \mathrm{s})$ is much large when compared to the shock pulse length [1]. For studying the elastic response, a pipe was inserted to the target assembly and strain gauge cables from the test plate were run through it to the data acquisition system. A rubber gasket was provided between the test plate and the flange to prevent leakage into the assembly. The air backed assemblies had a depth of $250 \mathrm{~mm}$ to accommodate the dynamic plastic deformation and possible fracture. Bolts were provided at the periphery to clamp the test plates.

A general purpose gauge CEA-06-125UW-120 and four CEA-06-125UT-120 T-rosettes were fixed on the circular plate as shown schematically in Fig. 1. A photographic view of the strain gauge arrangement on 


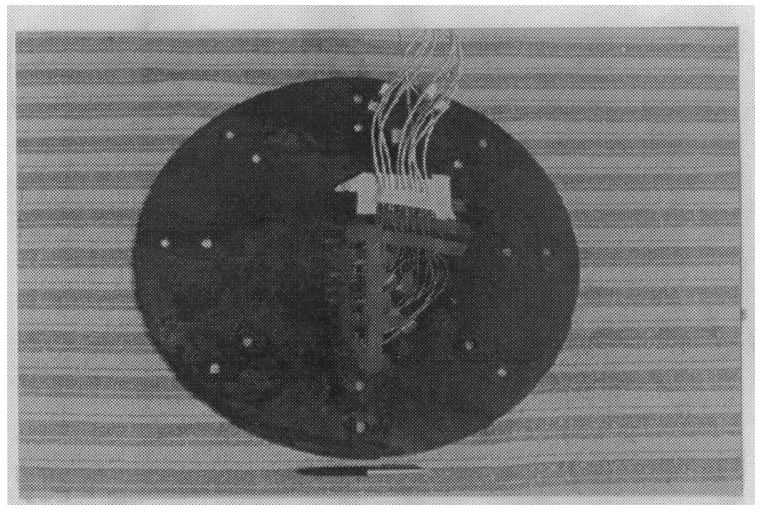

Fig. 2. Photographic view of the location of strain gauges on the HSLA steel circular plate.

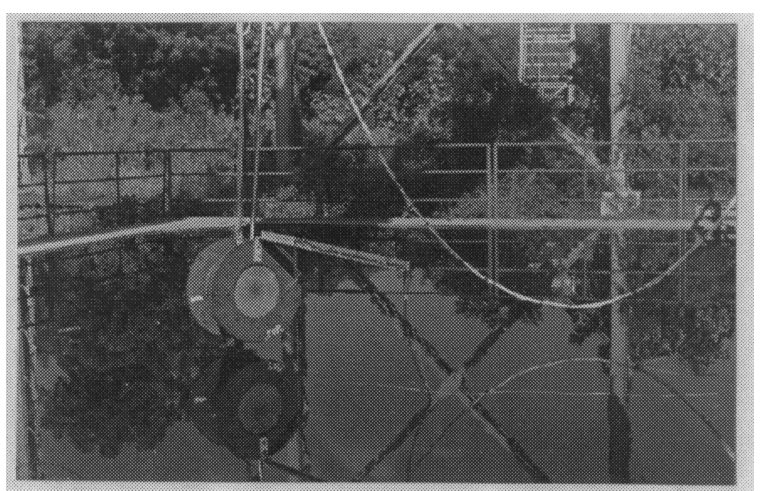

Fig. 3. Photographic view of the test assembly used for the dynamic strain experiments.

the test plate is shown in Fig. 2. The test plate was assembled into an air backed drum model target. A photographic view of this arrangement ready for firing is shown in Fig. 3. Bridge balancing [2] was done with $10 \mathrm{~V}$ as the excitation voltage as per the recommendations given in the Micro Measurements manual 2310 [16]. The schematic of the instrumentation set-up used for the experiments is shown in Fig. 4.

PEK-1 explosive (1.17 TNT equivalent) with Mk79 electric detonator was used for all the tests reported herein. The explosive was weighed, inserted in plastic container and positioned at required stand off such that its centre coincided with the centre of the plate. The electric detonator was inserted into the explosive. A firing cable was lead from the detonator to the firing circuit situated in the control room. The whole set up was submerged in the underwater shock tank $(15 \times 12 \times 10 \mathrm{~m})$ during experiments. Dynamic strain was recorded on 42 channel SE7000D tape recorder through Micro measurements 2310 amplifier and anal- ysed using Iwatsu SM 2100B signal analyser. All the strains were recorded and replayed at $720 \mathrm{~mm} / \mathrm{min}$.

A dial gauge arrangement (with an accuracy of $0.01 \mathrm{~mm}$ accuracy) was fixed on the existing MTS 886361 A shock testing system as shown in Fig. 5 for measuring the thickness reduction of plates subjected to plastic deformation. Fractured specimen were examined visually for finding out the microscopic mode of failure. Samples were also prepared for Scanning Electron Microscopic (SEM) examination using JEOL T330 A machine.

\section{Results and discussion}

\subsection{Elastic strain response}

The results of the strain analysis experiments are summarised in Table 3. A typical strain time history of the plate at its centre for a stand off of $1.2 \mathrm{~m}$ is shown in Fig. 6. The second peak of the dynamic strain [12] is greater than the first peak due to the addition of the gas bubble pulse on to the plate which has already begun to spring back from elastic deflection. The variation of the strain data due to the primary pulse for the stand off varying from $2 \mathrm{~m}$ to $60 \mathrm{~cm}$ as a function of the radial distance of the plate is shown in Fig. 7. Theoretically, the radial and the tangential strains must be equal due to equi-biaxial membrane stretching [7]. The experimental results closely follow the theoretical trend.

\subsection{Semi- analytical model}

The underwater shock energy transmitted per unit area for an air backed plate is [22]

$$
E_{d}=\frac{2 m P_{m}^{2}}{\rho^{2} c^{2}} x^{\frac{2}{x^{1-x}}}
$$

where $E_{d}$ is the energy density, $m$ is the mass per unit area of the plate, $P_{m}$ is the peak pressure, $\rho$ is the density of water and $c$ is the velocity of sound in the water medium and $x$ is inverse weight number which is equal to $\frac{\rho c \theta}{m}$ where $\theta$ is the time constant of the shock pulse. Since the mass per unit area can be given as the thickness times the mass density of the plate, Eq. (1) can be written as

$$
E_{d}=\frac{2 t \rho_{p} P_{m}^{2}}{\rho^{2} c^{2}} x^{\frac{2}{1-x}}
$$

where $\rho_{p}$ is the mass density and $t$ is the thickness of the plate. 


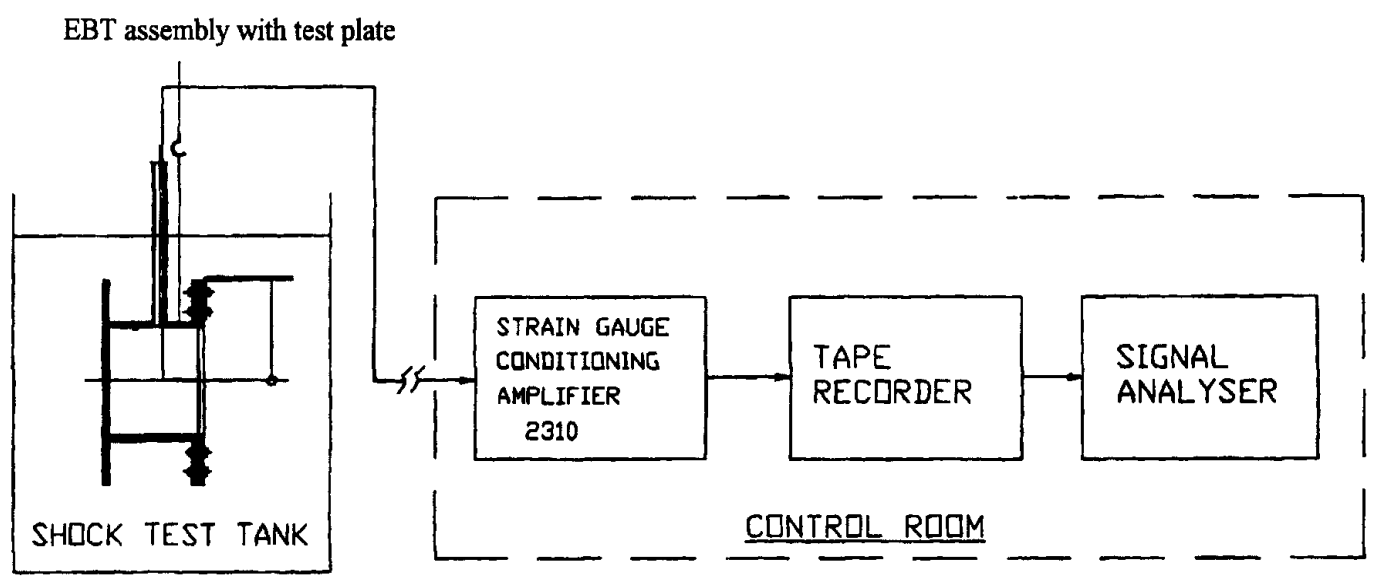

Fig. 4. Schematic of the experimental set up used for measuring the dynamic strains on the circular plate.

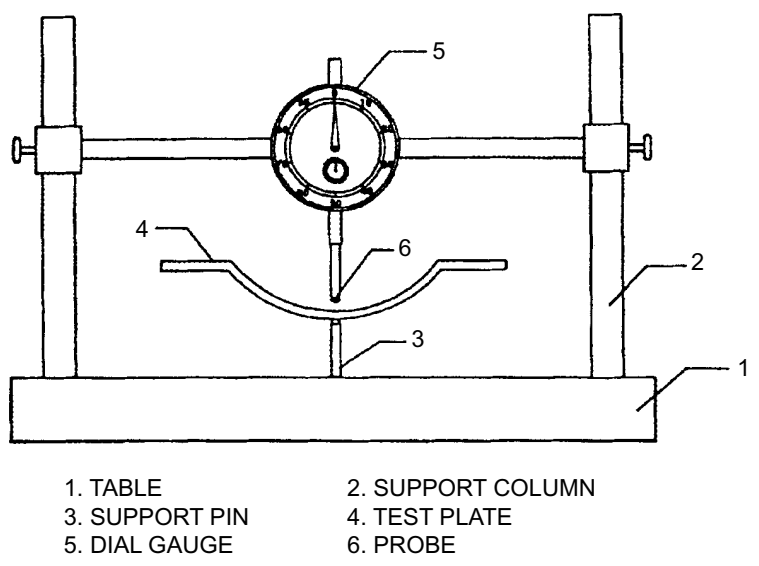

Fig. 5. Schematic of the dial gauge arrangement for measuring the depth of bulge and apex thickness strain.

The total energy transmitted to a circular plate of radius $R$ is

$$
E_{t}=\frac{2 t \rho_{p} P_{m}^{2} \pi R^{2}}{\rho^{2} c^{2}} x^{\frac{2}{1-x}}
$$

Since, a thickness up to approximately 5 per cent of the other dimensions such as diameter, length and width is considered as thin plate [15], it is assumed that the plate deforms like a membrane and all the bending effects are neglected. The strain energy density $U_{d}$ of the elastically deforming material in plane stress condition is given as

$$
U_{d}=\frac{1}{2}\left(\sigma_{1} \varepsilon_{1}+\sigma_{2} \varepsilon_{2}\right)
$$

where $\varepsilon_{1}, \varepsilon_{2}, \sigma_{1}$ and $\sigma_{2}$ have their usual meanings. Due to equibiaxial stretching $\sigma_{1}=\sigma_{2} ; \varepsilon_{1}=\varepsilon_{2}$. From the experimental data, it is observed that the tangential and radial strains vary in parobolic fashion with radial distance. Therefore, it is reasonable to propose the strain distribution function

$$
\varepsilon=\varepsilon_{a}\left(1-\frac{r^{2}}{R^{2}}\right)
$$

where $\varepsilon$ is the principal strain at any point on the plate, $\varepsilon_{a}$ is the apex principal strain and $r$ is the instantaneous radius. The elastic deformation strain energy for an incremental radius $d r$ of the plate is

$$
U=\int_{0}^{R} U_{d} t 2 \pi r d r
$$

Substituting for $U_{d}$ from Eq. (4) for equibiaxial membrane stretching and simplifying

$$
U=\frac{E t \varepsilon_{a}^{2} \pi R^{2}}{3(1-\nu)}
$$

where $E$ and $\nu$ are Young's modulus and Poisson's ratio respectively. It is assumed that all the kinetic energy of the plate is converted to strain energy. Equating the kinetic energy of the plate in Eq. (3) to the strain energy in Eq. (7), the apex principal strain is given as

$$
\varepsilon_{a}=\sqrt{\frac{6 \rho_{p} P_{m}^{2} x^{\frac{2}{1-x}}(1-\nu)}{E \rho^{2} c^{2}}}
$$

For plane stress condition, the von-Mises' stress [8] is given by

$$
\sigma^{2}=\sigma_{1}^{2}+\sigma_{2}^{2}-\sigma_{1} \sigma_{2}
$$

where $\sigma$ is the von-Mises' stress of the material. Equation (9) reduces to

$$
\sigma=\frac{E \varepsilon}{(1-\nu)}
$$


Table 3

Summary of results of dynamic elastic strain experiments on the circular plate; Charge quantity $=$ $0.01 \mathrm{~kg}$ of PEK-1 explosive

\begin{tabular}{|c|c|c|c|c|c|c|c|c|c|c|}
\hline S1 No & $\begin{array}{c}\text { Stand } \\
\text { off S } \\
(\mathrm{m})\end{array}$ & $\begin{array}{c}\text { SA } \\
(\mu \varepsilon)\end{array}$ & $\begin{array}{l}\text { S2A } \\
(\mu \varepsilon)\end{array}$ & $\begin{array}{l}\text { S2B } \\
(\mu \varepsilon)\end{array}$ & $\begin{array}{l}\text { S3A } \\
(\mu \varepsilon)\end{array}$ & $\begin{array}{l}\text { S3B } \\
(\mu \varepsilon)\end{array}$ & $\begin{array}{l}\mathrm{S} 4 \mathrm{~A} \\
(\mu \varepsilon)\end{array}$ & $\begin{array}{l}\text { S4B } \\
(\mu \varepsilon)\end{array}$ & $\begin{array}{l}\text { S5A } \\
(\mu \varepsilon)\end{array}$ & $\begin{array}{l}\text { S5B } \\
(\mu \varepsilon)\end{array}$ \\
\hline 1. & 2.0 & 526 & 503 & 489 & 436 & 421 & 323 & 308 & 166 & 183 \\
\hline 2. & 1.8 & 583 & 558 & 562 & 483 & 492 & 359 & 374 & 184 & 198 \\
\hline 3. & 1.6 & 688 & 659 & 641 & 570 & 582 & 428 & 420 & 216 & 232 \\
\hline 4. & 1.4 & 789 & 755 & 738 & 654 & 661 & 485 & 473 & 249 & 243 \\
\hline 5. & 1.2 & 928 & 894 & 883 & 782 & 720 & 525 & 521 & 294 & 245 \\
\hline 6. & 1.0 & 1123 & 1075 & 1054 & 931 & 928 & 690 & 697 & 354 & 371 \\
\hline 7. & 0.8 & 1331 & 1226 & 1205 & 1136 & 1136 & 883 & 808 & 461 & 490 \\
\hline 8. & 0.6 & 1828 & 1720 & 1650 & 1508 & 1534 & 1134 & 1145 & 636 & 671 \\
\hline \multicolumn{11}{|c|}{$\begin{array}{l}\text { A-Tangential } \\
\text { B-Radial } \\
\text { SA-Centre of the plate } \\
\text { S2-30 mm from the centre of the plate } \\
\text { S3-60 mm from the centre of the plate } \\
\text { S4-90 } \mathrm{mm} \text { from the centre of the plate } \\
\text { S5-120 mm from the centre of the plate }\end{array}$} \\
\hline
\end{tabular}

Table 4

Summary of underwater explosion parameters for elastic strain experiments on the circular plate; Charge quantity $=0.01 \mathrm{~kg}$ of PEK-1 explosive

\begin{tabular}{|c|c|c|c|c|c|c|c|c|c|}
\hline S1 No. & $\begin{array}{c}\text { Stand } \\
\text { off S } \\
(\mathrm{m})\end{array}$ & $\begin{array}{c}\text { Peak } \\
\text { pressure } \\
(\mathrm{MPa})\end{array}$ & $\begin{array}{c}\text { Time } \\
\text { constant } \\
(\mu s)\end{array}$ & $\begin{array}{c}\mathrm{X} \\
(\rho \mathrm{c} \theta / \mathrm{m})\end{array}$ & $x^{\frac{2}{1-x}}$ & $\begin{array}{c}\text { Experimental } \\
\text { apex } \\
\text { strain } \\
(\mu \varepsilon)\end{array}$ & $\begin{array}{l}\text { Semi- } \\
\text { analytical } \\
\text { apex } \\
\text { strain } \\
(\mu \varepsilon)\end{array}$ & $\begin{array}{c}\text { Difference } \\
\text { between semi- } \\
\text { analytical and } \\
\text { experimental } \\
\text { apex strain } \\
(\%)\end{array}$ & $\begin{array}{c}\text { Semi- } \\
\text { analytical } \\
\text { von-Mises' } \\
\text { stress }\end{array}$ \\
\hline 1. & 2.0 & 4.462 & 35.39 & 1.702 & 0.2197 & 526 & 573 & 8.2 & 170 \\
\hline 2. & 1.8 & 5.026 & 34.58 & 1.662 & 0.2156 & 581 & 617 & 5.8 & 183 \\
\hline 3. & 1.6 & 5.742 & 33.70 & 1.620 & 0.2109 & 688 & 693 & 0.7 & 206 \\
\hline 4. & 1.4 & 6.667 & 32.72 & 1.573 & 0.2058 & 789 & 801 & 1.5 & 238 \\
\hline 5. & 1.2 & 7.947 & 31.63 & 1.521 & 0.2000 & 928 & 940 & 1.3 & 279 \\
\hline 6. & 1.0 & 9.765 & 30.63 & 1.461 & 0.1931 & 1123 & 1134 & 0.5 & 337 \\
\hline 7. & 0.8 & 12.556 & 28.93 & 1.391 & 0.1843 & 1331 & 1429 & 6.8 & 425 \\
\hline 8. & 0.6 & 17.393 & 27.16 & 1.306 & 0.1746 & 1828 & 1921 & 4.8 & 571 \\
\hline
\end{tabular}

since $\sigma_{1}$ and $\sigma_{2}$ are equal due to membrane stretching.

The summary of semi-analytically estimated strains with underwater explosion parameters for circular plates is shown in Table 4. A comparison is made between the von-Mises semi-analytical stress with the experimental stress in Fig. 8. There is good correlation between the semi-analytical model and the experimental results.

\subsection{Dynamic yield response}

\subsubsection{Shock factor for yielding}

The shock factor $S F$ [13] is given as $0.445 \frac{\sqrt{W}}{S}$ where $W$ is the charge quantity in $k g$ and $S$ is the stand off in $m$. Reducing the stand off from $60 \mathrm{~cm}$ to $57 \mathrm{~cm}$ resulted in permanent deflection of $2 \mathrm{~mm}$ at the centre of the plate. By assuming that the elastic limit of the plate merged with its yield limit, it can be safely stated that the plate starts yielding at $60 \mathrm{~cm}$ stand off. The corresponding shock factor is 0.08. From Eq. (7) and (10), it can be seen that the strain energy per unit area of a plate at yielding is a function of its thickness, Poisson's ratio and yield stress:

$$
\sqrt{U} \propto \sigma_{y} \sqrt{\frac{(1-\nu) t}{E}}
$$

The ratio of the energy transmitted to the plate to the energy of the incident shock wave is given as [1] $4 x^{\frac{1+x}{1-x}}$ which can be called as 'coupling factor, $\eta$ '. Since the shock factor is a measure of square root of incident energy,

$$
S F \sqrt{\eta}=Y F \sigma_{y} \sqrt{\frac{t(1-\nu)}{E}}
$$




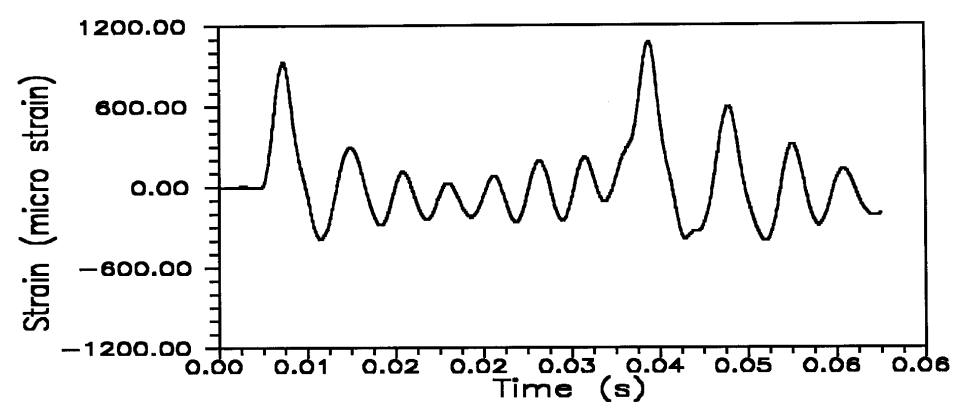

Fig. 6. A typical strain time history recorded on the circular plate. Charge weight $=10 \mathrm{~g}$ of PEK-1; stand off $=1.2 \mathrm{~m}$; Location: centre of the plate.

Table 5

Summary of results of plastic deformation experiments on circular plates; stand off

\begin{tabular}{ccccc}
$=15 \mathrm{~cm}$ & \multicolumn{5}{c}{} \\
\hline Shot No. & $\begin{array}{c}\text { Charge quantity of } \\
\text { PEK-1 }(\text { gram })\end{array}$ & $\begin{array}{c}\text { Free field impulse } \\
\left(\mathrm{Ns} / \mathrm{m}^{2}\right)\end{array}$ & $\begin{array}{c}\text { Depth of bulge } \\
(\mathrm{mm})\end{array}$ & $\begin{array}{c}\text { Thinning } \\
(\%)\end{array}$ \\
\hline 1. & 5 & 1221 & 10.1 & 1.2 \\
2. & 10 & 1891 & 20.6 & 2.1 \\
3. & 15 & 2441 & 26.2 & 3.3 \\
4. & 20 & 2926 & 29.2 & 4.3 \\
5. & 30 & 3778 & 40.0 & 7.3 \\
6. & 40 & 4528 & 49.0 & 11.5 \\
7. & 50 & 5212 & 56.0 & 16.0 \\
8. & 60 & 5846 & 62.0 & 17.1 \\
9. & 70 & 6442 & 71.0 & 21.5 \\
10. & 80 & 7008 & Rupture & 22.3 \\
\hline
\end{tabular}

Table 6

Summary of validation experiment results in comparison with empirical prediction for circular plates

\begin{tabular}{cccrcc}
\hline Shot No. & $\begin{array}{c}\text { Charge quantity } \\
\text { of PEK-1 } \\
(\text { gram })\end{array}$ & $\begin{array}{c}\text { Stand off } \\
(\mathrm{cm})\end{array}$ & $\Phi_{c}$ & $\delta_{\text {ex }}$ & $\delta_{\text {em }}$ \\
\hline 1. & 30 & 20 & 15.00 & 31.0 & 29.2 \\
2. & 40 & 20 & 17.98 & 37.4 & 37.2 \\
3. & 50 & 20 & 20.07 & 40.3 & 41.0 \\
4. & 60 & 20 & 23.20 & 46.1 & 48.6 \\
5. & 50 & 30 & 14.42 & 31.0 & 29.2 \\
6. & 50 & 40 & 11.17 & 22.7 & 21.6 \\
7. & 50 & 50 & 9.16 & 15.6 & 18.3 \\
8. & 60 & 40 & 12.52 & 24.3 & 25.6 \\
9. & 60 & 50 & 10.27 & 19.2 & 20.7 \\
\hline
\end{tabular}

where $Y F$ (which may be called as yield factor is a constant which corresponds to the yield condition of the plate. Substituting the relevant values,

$$
S F=1.2606 * 10^{-3} \frac{1}{\sqrt{\eta}} \sigma_{y} \sqrt{\frac{t(1-\nu)}{E}}
$$

The variation of inverse square root of the coupling factor as a function of inverse weight number is shown in Fig. 9 for ready reference. From Eq. (13), the shock factor for yielding for any thin circular steel plate can be readily obtained for a given time constant of the shock pulse once its thickness and material properties are known.

\subsubsection{Dynamic yield stress}

The von-Mises' stress for yielding computed from Eq. (10) for the yield onset is the dynamic yield stress of the plate which is equal to $546 \mathrm{MPa}$. Cowper-Symond's equation [19] states for steel like material

$$
\sigma_{y d}=\sigma_{y}\left[1+\left\{\frac{\dot{\varepsilon}}{D}\right\}^{1 / n}\right]
$$

where $\sigma_{y}$ is the static yield stress, $\dot{\varepsilon}$ is the strain rate, $D$ is the constant having a value of 40 and $n$ is another constant having the value of 5 .

The average strain rate encountered in the experiment was $0.5 \mathrm{~s}^{-1}$. Substituting this value in Eq. (14), $\sigma_{y d}$ is obtained as $567 \mathrm{MPa}$ (Static yield stress for the HSLA steel is $400 \mathrm{MPa}$ ). The discrepancy between the strain rate based dynamic yield stress and the strain based dynamic yield stress is 3.8 per cent.

\subsection{Plastic response}

The results of underwater explosion bulge test for the plastic deformation of the circular plates are shown in 


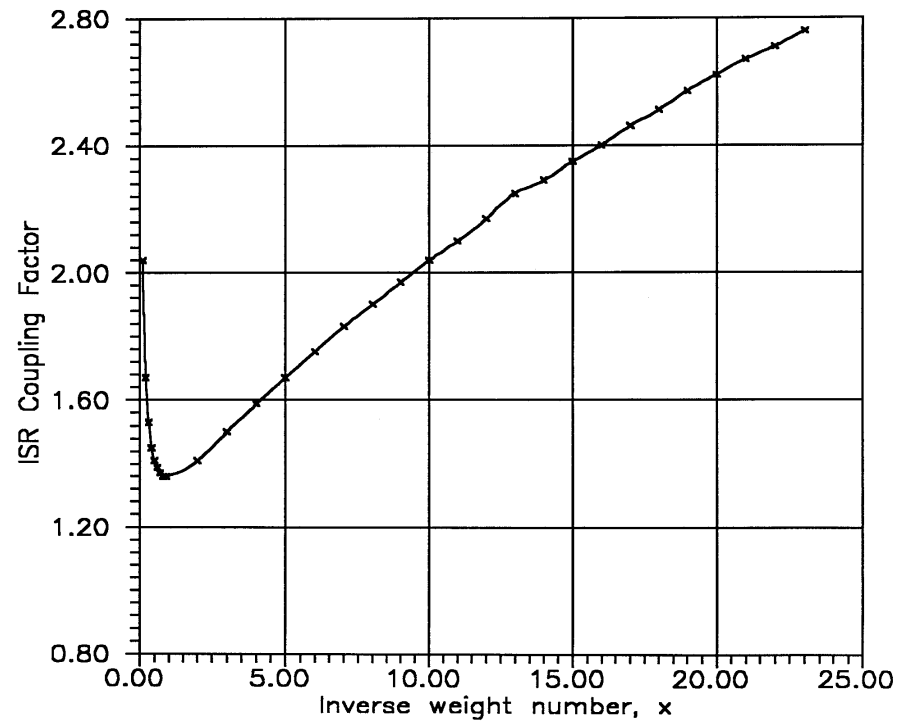

Fig. 9. Variation of the inverse square root of the coupling factor as a function of inverse weight number, $\mathrm{x}$.

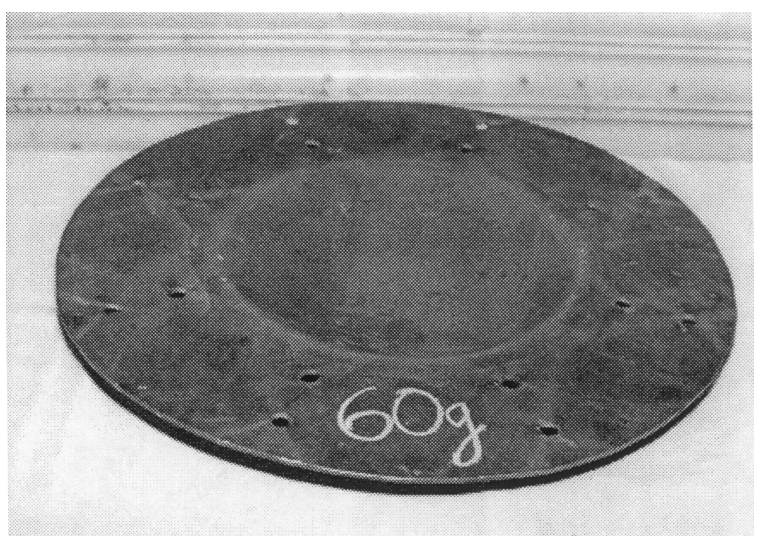

Fig. 10. A photographic view of the plastically deformed plate; explosive charge weight $=60$ grams of PEK-1; stand off $=150 \mathrm{~mm}$.

Table 5. The thickness reduction varied from 1.25 per cent to 21.25 per cent before fracture. The deflectionthickness ratio varied from 2.525 to 17.75 . A photographic view of the plate deformed during underwater explosion for a charge quantity of 60 grams of PEK-1 is shown in Fig. 10. The variation of thickness strain as a function of deflection of the apex of the plate is shown in Fig. 11.

\subsubsection{Empirical prediction}

The dimensionless number proposed by Nurick [17, 18] for circular plate takes in to account the total impulse acting on the plate. However, in underwater explosion, the total impulse acting on the plate is not easily derivable since there are reflection and rarefac-

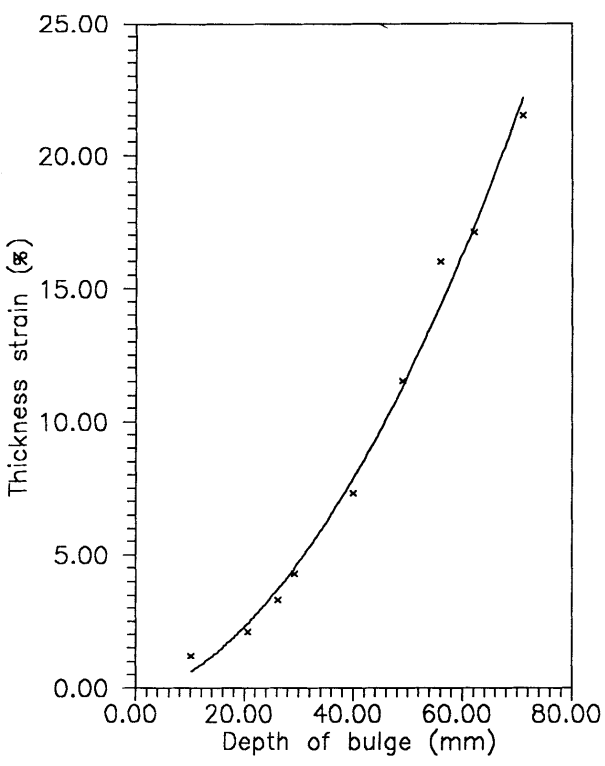

Fig. 11. Variation of thickness strain as a function of deflection at the apex of the plate.

tion components which modify the incident pressure pulse [14] both in magnitude and direction. Therefore the dimensionless parameter is derived as a function of free field impulse acting on the plate.

$$
\Phi_{c}=\frac{I_{f}}{\pi R t^{2}\left(\rho_{p} \sigma_{y}\right)^{1 / 2}} \pi R^{2}
$$

where $I_{f}$ is the free field impulse which is given by

$$
I_{f}=5760\left(\frac{W^{0.63}}{S^{0.89}}\right)
$$




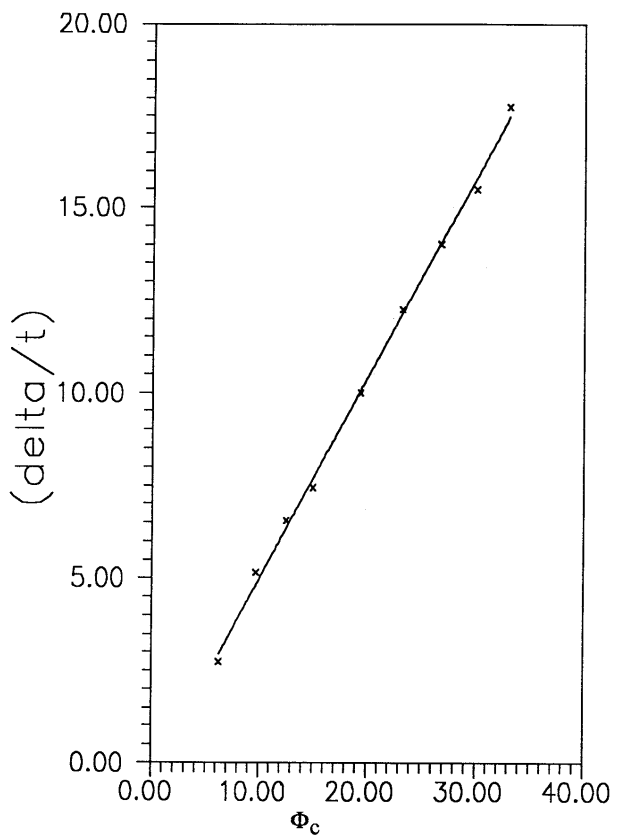

Fig. 12. Variation of deflection - thickness ratio as a function of dimensionless parameter $\Phi_{c}$.

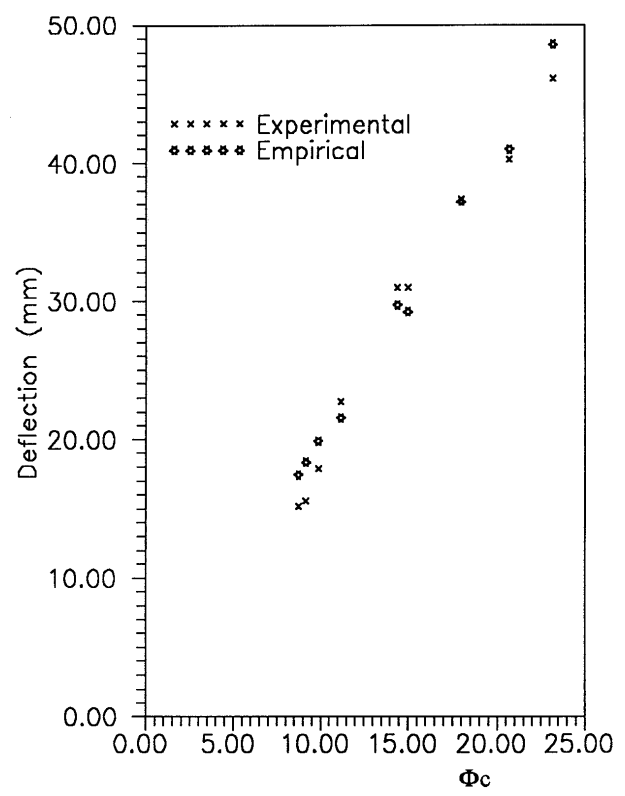

Fig. 13. A comparison of empirical prediction with experimental data for plastic deformation.

where $W$ is the TNT equivalent of the explosive charge quantity in $\mathrm{kg}$ and $S$ is the stand off in $m$.

Graphical representation of deflection -thickness ratio as a function of the dimensionless parameter $\Phi_{c}$ is shown in Fig. 12. Linear curve fitting is made to the

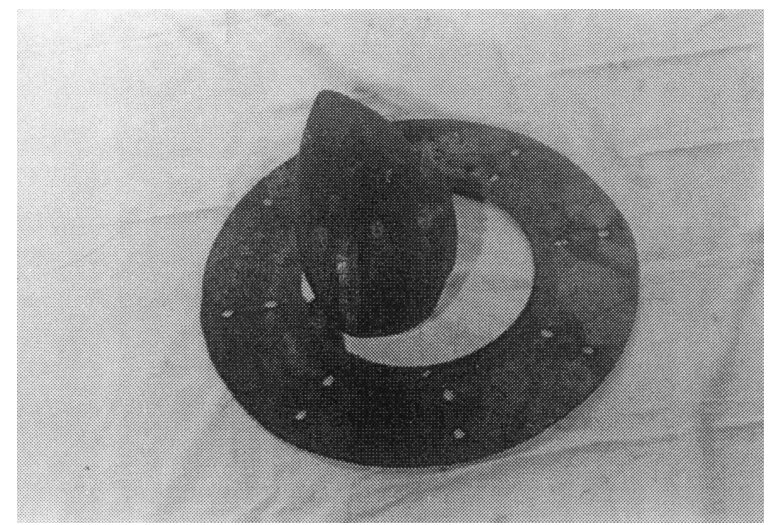

Fig. 14. A photographic view of the plate fractured at its edge; explosive charge quantity $=80$ grams of PEK-1. Stand off $=150 \mathrm{~mm}$.

data since the deflection is proportional to the impulse on the plate [1]. The deflection - thickness ratio is given as

$$
\left(\frac{\delta}{t}\right)=0.541 \Phi_{c}-0.433
$$

\subsubsection{Model validation}

In order to see the applicability of the empirical model, a separate set of underwater explosion experiments were carried out on the circular plate with different charge quantities and stand offs. The results of the second set of experiments are summarised in Table 6 and shown graphically in Fig. 13. The explosive charge quantity was varied from 30 to 60 grams of PEK-1 and the stand off was varied from $20 \mathrm{~cm}$ to $50 \mathrm{~cm}$. The experimental central deflection data has shown an agreement of 85 to 99.5 per cent with the empirical prediction. This shows that the empirical model makes excellent prediction over a wide range of explosive quantities and stand offs.

\subsection{Fracture analysis}

A photographic view of the circular plate fractured at its edge as inferred by Fox [6] is shown in Fig. 14 The plate fractured all around its edge. A closer view of the failed edge is shown in Fig. 15. From Fig. 15, it is observed that the failure of the plate was slant fracture across the thickness of the plate which is typical of ductile failure [8]. The fractured surface was brownish yellow in colour suggesting heavy oxidation due to the heat generated by the dynamic plastic deformation. Scanning Electron Microscopic (SEM) fractography of the failed sample is shown in Fig. 16. Dimple features show that the fracture was by micro void coalescence. 


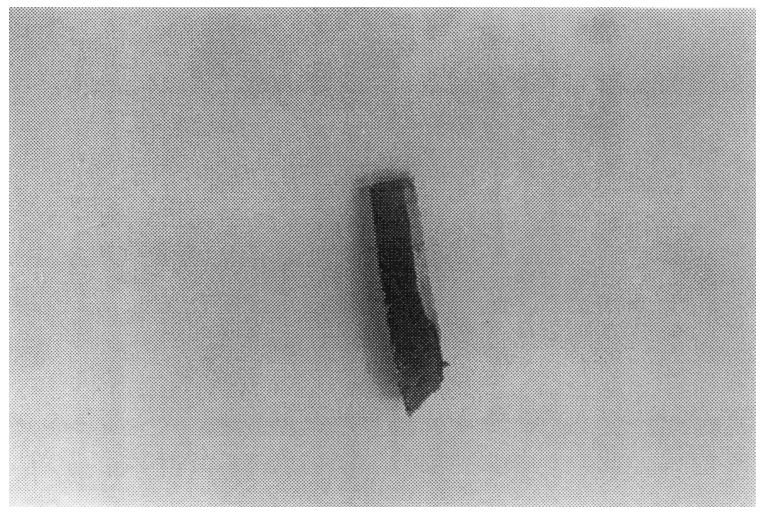

Fig. 15. A close view of the failed edge of the plate; slant fracture s seen on the surface.

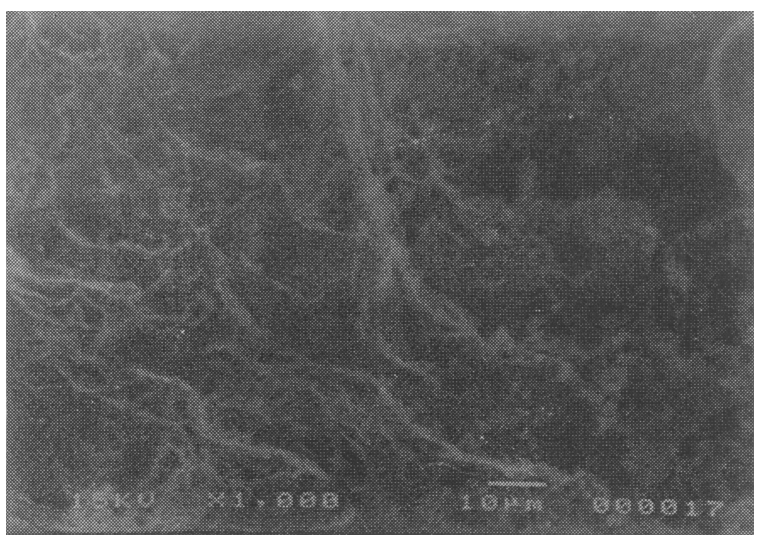

Fig. 16. Scanning Electron Microscopic (SEM) fractography of the failed plate; dimple features show ductile fracture.

This corroborates the observation of the macroscopic examination. The fracture strain at the apex of the plate was 22.3 per cent.

\section{Conclusions}

Underwater explosion experiments were carried out on a circular HSLA steel plate and dynamic radial and tangential strains were recorded to derive a strain energy function for the variation of the apex strain as a function of radial distance. A semi-analytical model was developed for predicting the strain on the circular plate by equating the kinetic energy to the strain energy of the plate. This model takes into account the shock wave parameters, the plate elastic properties, material density and thickness and the acoustic properties of the water medium. A comparison is made between the semi-analytical prediction and the experimental result which show excellent agreement.
The shock factor for dynamic yielding was established. This serves as the dynamic yield prediction technique for a given thin circular steel plate when subjected to underwater explosion of a specific time constant of the pressure pulse. The dynamic yield stress of the plate is estimated as $546 \mathrm{MPa}$. The strain rate based yield stress is $567 \mathrm{MPa}$. The deviation of 3.8 per cent is due to the approximation made in determining the point of onset of yield.

An empirical model was developed for predicting the central deflection of the circular plate. This model was validated by carrying out explosions with different charge quantities and stand offs. There was a comparison of 85 to 99.5 per cent between the empirical model and the experiments. The empirical model could serve as design guideline for predicting the dynamic plastic deformation of a circular plate when subjected to an underwater explosion of an arbitrary explosive quantity at an arbitrary stand off.

Fracture analysis was carried out on the failed circular plate. The macroscopic mode of failure was slant suggesting ductile fracture which was corroborated by scanning electron microscopic fractography.

\section{References}

[1] R.H. Cole, Underwater Explosions, Princeton University Press, NJ, USA, 1948.

[2] J.W. Dally and W.F. Riley, Experimental Stress Analysis, McGraw Hill Kogakusha Ltd, 1978.

[3] G.E. Dieter, Mechanical Metallurgy, Mc Graw-Hill Publishers, Singapore, 1988.

[4] A.A. Ezra, Principles and Practice of Explosive Metal Working, (vol. 1), Industrial News Papers Ltd., John Adams House, Adelphi, London, WC2N 6JH, 1973.

[5] T.M. Finnie, Explosive Forming of Circular Diaphragms, Sheet Metal Industries, 1962, pp. 391-398.

[6] E.N. Fox, A Review of Underwater Explosion Phenomena, Compendium of Underwater Explosion Research 1 (1947), $1-83$.

[7] A.N. Glezal, Plastic deformation and Absorption of Energy by Thin Circular Plates Under Normal Loading, Compendium of Underwater Explosion Research, ONR 3 (1951), 143-152.

[8] R.W. Hertzberg, Deformation and Fracture Mechanics of Engineering Materials, (Third ed.), John Wiley \& SonsInc., New York, 1989.

[9] W. Johnson, A. Poyton, H. Singh and F.W. Travis, Experiments in the Underwater Explosion Stretch Forming of Clamped Circular Blanks, International Journal of Mechanical Sciences 8 (1966), 237-270.

[10] W. Johnson, K. Kormi and F.W. Travis, An Investigation into the Explosive Deep Drawing of Circular Blanks Using Plug Cushion Technique, International Journal of Mechanical Sciences 6 (1964), 287-301.

[11] R.A. Jones and Y.S. Shin, Experimental Investigation of the Response and Failure Mechanisms of Circular Metal and Composite Plates to Underwater Explosion, 61st Shock and Vibration Bulletin 3 (1992), 163-178. 
[12] A.H. Keil, Introduction to Underwater Explosion Research, UERD, Norfolk Naval Ship Yard, Portsmouth, Virginia, 1956.

[13] A.H. Keil, The Response of Ships to Underwater Explosions, Transactions of Society of Naval Architects and Marine Engineers 69 (1961), 366-410.

[14] A.H. Kennard, The Effect of Pressure Wave on a Plate or Diaphragm, Compendium of Underwater Explosion Research, ONR 3 (1944), 11-64.

[15] D. Mc Farland, B.L. Smith and W.D. Bernhart, Analysis of Plates, Sparton Books, New York, 1972.

[16] Micro Measurements Strain Gauge Conditioning Amplifier, 2310 Instruction Manual, 1985.

[17] G.N. Nurick and J.B. Martin, Deformation of Thin Plates Subjected to Impulsive 16. Loading-A Review, Part II: Experimental Studies, International Journal of Impact Engineering 8(2) (1989), 171-186.

[18] G.N. Nurick, An Empirical Solution for Predicting Maximum Central Deflection of Impulsively Loaded Plates, International Conference on Mechanical Properties of Materials at High
Rates of Strain, Oxford, Institute of Physics Society, No. 12 Session 9, 1989.

19] N. Perrone and B. Bhadra, A Simplified Method to Account for Plastic Rate Sensivity With Large Deformations, ASME Journal of Applied Mechanics 46 (1979), 811-815.

[20] J.R. Remmerswaal, The Peaceful Use of Explosives, Sheet Metal Industries (1962), 475-486.

[21] R.G. Smith and G.N. Nurick, Deformation and Rupture of Blast Loaded Circular Plates - Predictions and Experiments, International Journal of Impact Engineering 11(1) (1991), 77-91.

[22] G.I. Taylor, The Pressure and Impulse of submarine Explosion Waves on plates, Compendium of Underwater Explosion Research, ONR 1(1941), 1155-1124.

[23] F.W. Travis and W. Johnson, Experiments in the Dynamic Deformation of Clamped Circular Sheets of Various Metals Subject to Underwater Explosive Charge, Sheet Metal Industries 39 (1961), 456-474. 

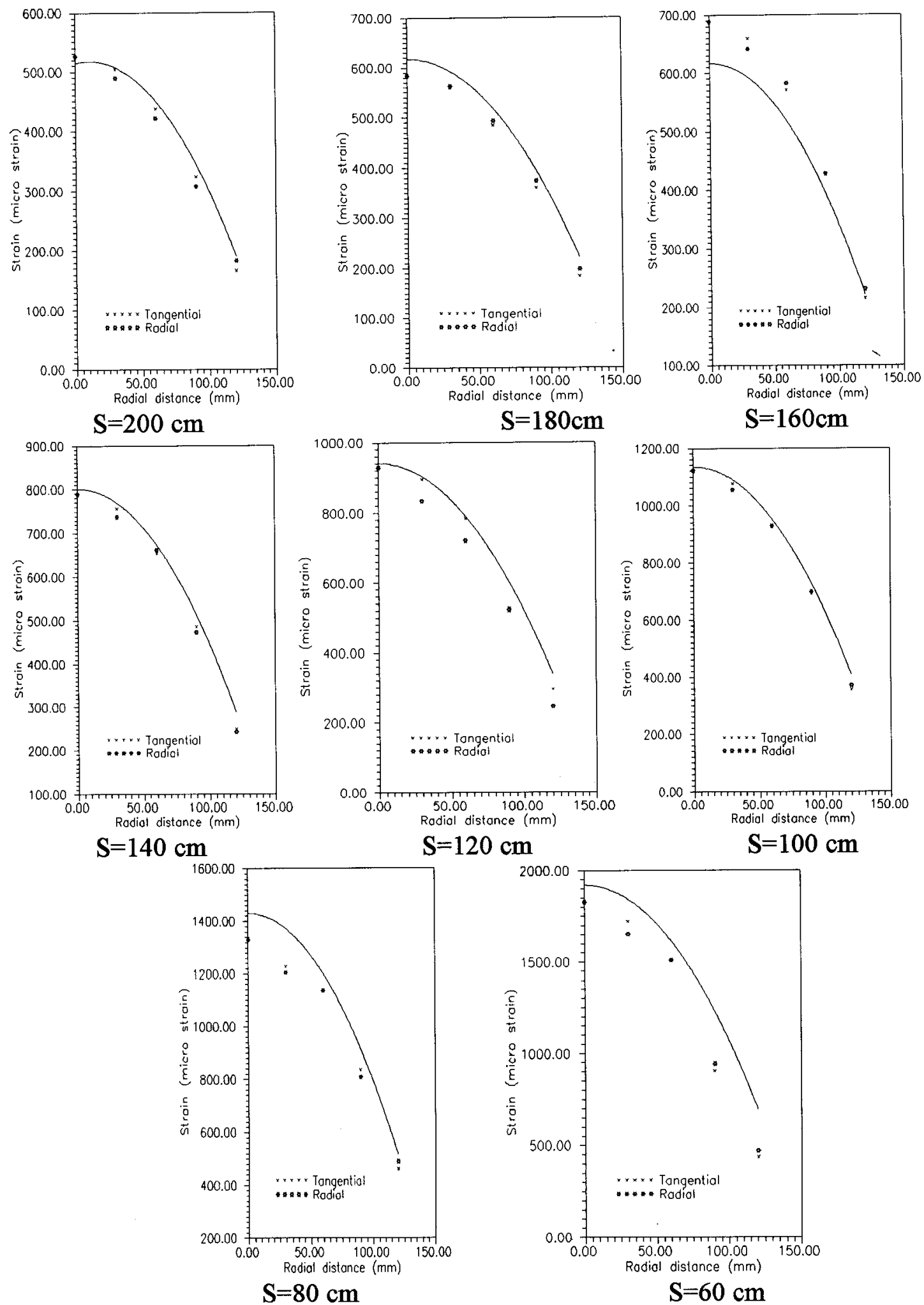

Fig. 7. Variation of tangential and radial strains along the radius of the circular plate. $\mathrm{S}$ is stand off. 

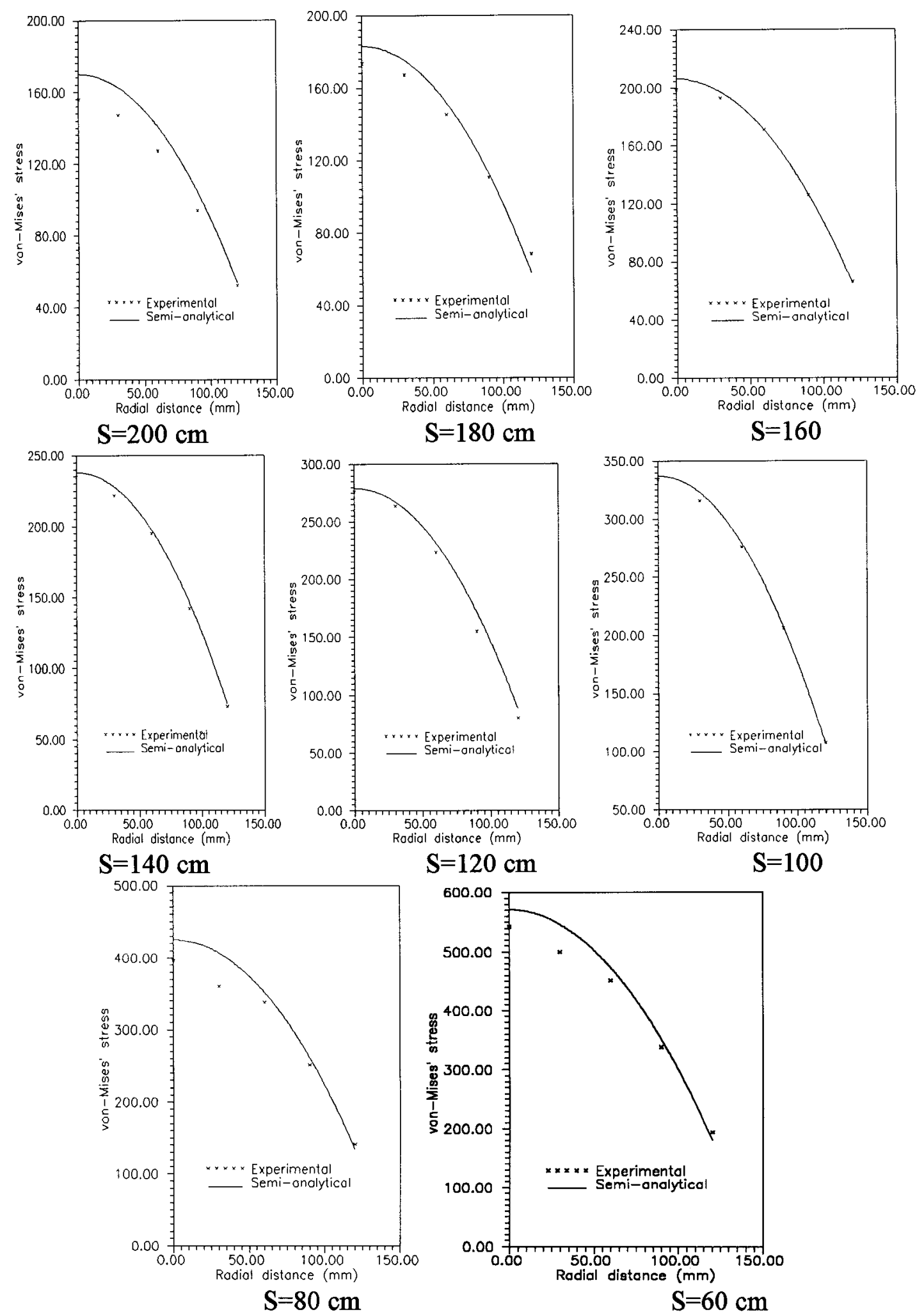

Fig. 8. Variation of von-Mises' stress along the radius of the circular plate. S is stand off. 

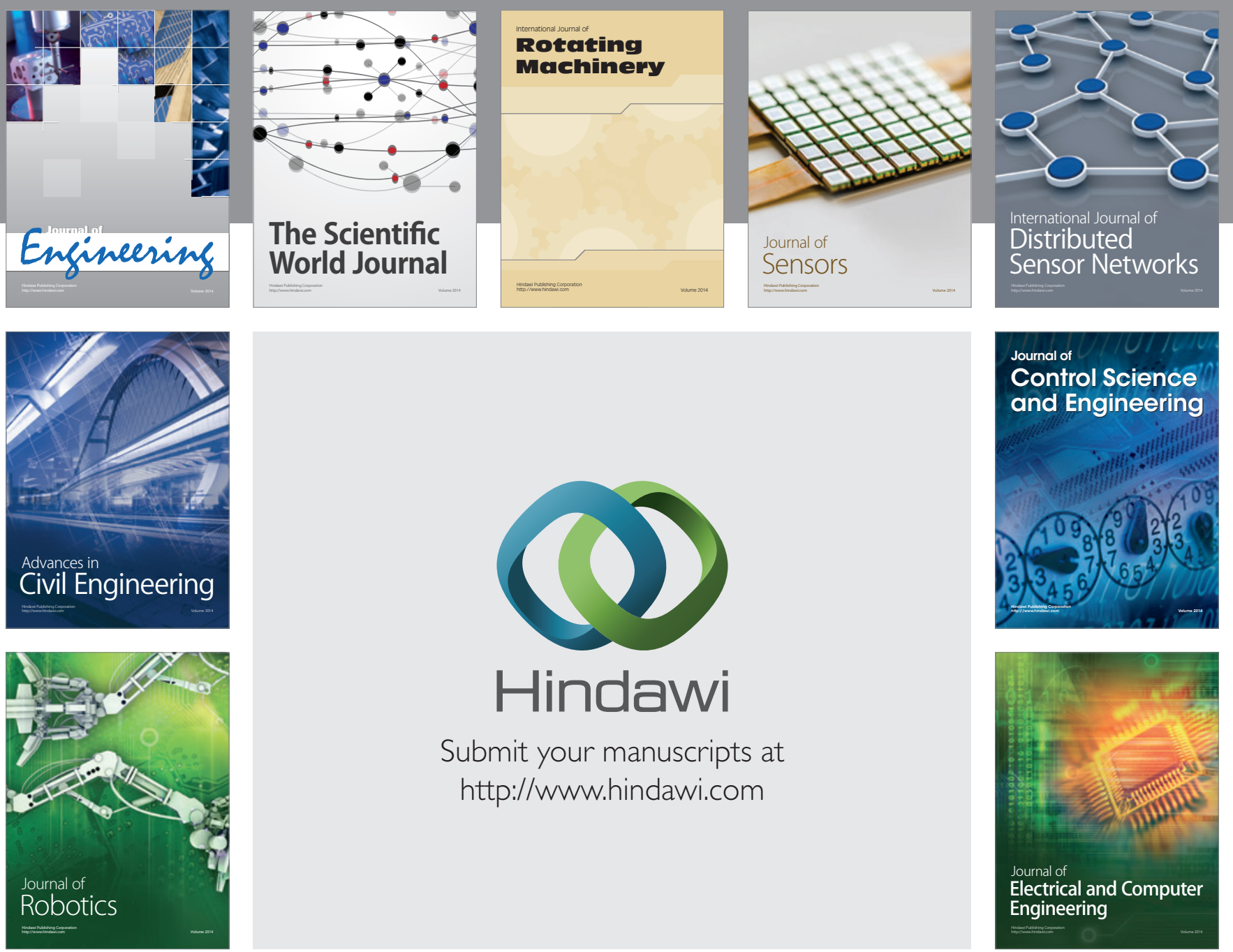

Submit your manuscripts at

http://www.hindawi.com
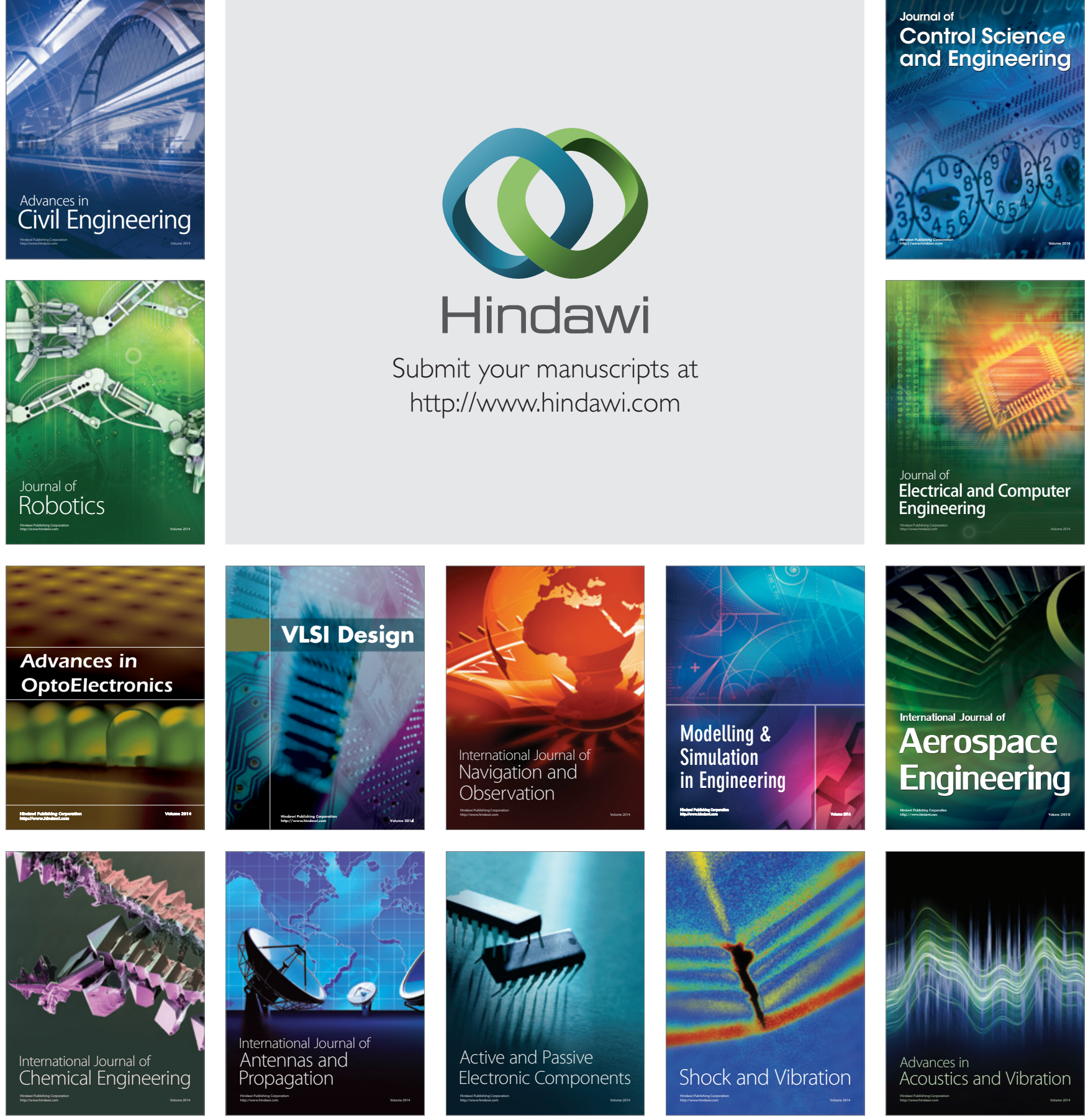